\title{
Early Versus Delayed Initiation of Salvage Androgen Deprivation Therapy and Risk of Prostate Cancer-Specific Mortality
}

\author{
Brandon A. Mahal, MDª Ming-Hui Chen, $\mathrm{PhD}^{\mathrm{b}}$; Andrew A. Renshaw, MDc; \\ Marian J. Loffredo, RN, BS, OCN'; Philip W. Kantoff, MD'; and Anthony V. D’Amico, MD, PhD
}

\begin{abstract}
Background: This study sought to ascertain whether there is an association between prostate cancer (PC)-specific mortality (PCSM) and timing of salvage androgen deprivation therapy (ADT) among men with short versus long prostate-specific antigen doubling times (PSA-DTs). Methods: The study cohort was selected from 206 men with localized unfavorable-risk PC randomized to radiation therapy (RT) or RT plus 6 months of ADT between 1995 and 2001. A total of 54 men who received salvage ADT for PSA failure after a median follow-up of 18.72 years following randomization defined the study cohort. The Fine-Gray competing risks regression model was used to analyze whether the timing of salvage ADT was associated with an increased risk of PCSM after adjusting for age, comorbidity, known PC prognostic factors, and previously identified interactions. Results: After a median follow-up of 5.68 years (interquartile range, 3.05-9.56) following salvage ADT, 49 of the 54 men ( $91 \%$ ) died, of which 27 from PC (54\% of deaths). Increasing PSA-DT as a continuous covariate (per month increase) was associated with a decreasing risk of PCSM (adjusted hazard ratio [HR], 0.33; $95 \%$ Cl, 0.13-0.82; $P=.02$ ). Among men with a long PSA-DT ( $\geq 6$ months), initiating salvage ADT later (PSA level $>12 \mathrm{ng} / \mathrm{mL}$, upper quartile) versus earlier was associated with an increased risk of PCSM (adjusted HR, 8.84; 95\% Cl, 1.99-39.27; $P=.004$ ), whereas for those with a short PSA-DT ( $<6$ months; adjusted HR, 1.16; 95\% Cl, 0.38-3.54; $P=.79$ ) this was not true. Conclusions: Early initiation of salvage ADT for post-RT PSA failure in men with a PSA-DT of $\geq 6$ months may reduce the risk of PCSM.
\end{abstract}

J Natl Compr Canc Netw 2018;16(6):727-734 doi: $10.6004 / j n c c n .2018 .7010$

\section{Background}

Prostate cancer (PC) is the most common noncutaneous malignancy in men, with 161,360 new cases and 26,730 deaths due to $\mathrm{PC}$ in 2017. ${ }^{1}$ Although radical prostatectomy $(\mathrm{RP})$ or radiation therapy $(\mathrm{RT})$ with or without androgen deprivation therapy (ADT) are often curative treatments for localized disease, ${ }^{2-5}$ approximately onequarter of patients will experience recurrence within 10 years after curative-intent therapy. ${ }^{6,7}$ An increasing prostate-specific antigen (PSA) level identifies men with biochemical recurrence defined as nadir +2 follow-

\footnotetext{
aDepartment of Radiation Oncology, Brigham and Women's Hospital/DanaFarber Cancer Institute, Boston, Massachusetts; 'bepartment of Statistics, University of Connecticut, Storrs, Connecticut; 'Division of Pathology, Miami Baptist Hospital, Miami, Florida; and dDepartment of Medicine, Memorial Sloan Kettering Cancer Center, New York, New York.

Submitted October 6, 2017; accepted for publication January 25, 2018.

The authors have disclosed that they have no financial interests,

arrangements, affiliations, or commercial interests with the manufacturers of any products discussed in this article or their competitors.
}

ing RT, or as detectable and increasing following RP., 8 Although ADT has been standard treatment when combined with RT in men with unfavorable (intermediate or high)-risk localized PC, ${ }^{5}$ recent evidence shows that adding ADT to RT provides a progression-free and overall survival benefit in men with biochemically recurrent increasing PSA levels after RP. ${ }^{10,11}$ However, level 1 evidence is lacking to guide management for patients with a biochemical recurrence after definitive treatment with RT with or without ADT.

Author contributions: Study conception and design: All authors. Drafting and critical revision: All authors. Technical, administrative, and/or material support: All authors. D'Amico and Chen had full access to all the study data and take responsibility for the integrity of the data and accuracy of the analyses.

Correspondence: Brandon A. Mahal, MD, Department of Radiation Oncology, Brigham and Women's Hospital/Dana-Farber Cancer Institute, 75 Francis Street, Boston, MA 02115.

Email: brandon_mahal@dfci.harvard.edu 
Moreover, the optimal timing of ADT initiation after post-RT biochemical recurrence remains an open question given the lack of randomized data comparing this approach with surveillance, and therefore the unknown impact of salvage ADT use on survival. To help guide timing of ADT initiation after biochemical recurrence, the NCCN Clinical Practice Guidelines in Oncology (NCCN Guidelines) for Prostate Cancer recommend that patients with a short PSA doubling time (PSA-DT) and an otherwise long life expectancy be encouraged to consider earlier ADT. ${ }^{2,12-15}$ However, an alternative hypothesis is that patients with favorable risk factors such as long PSA-DT and interval to PSA recurrence and Gleason score $\leq 7$ may be the ones who would have the potential for improved cancerspecific outcomes given that the recurrence may be less likely to be castration-resistant.

Therefore, the purpose of our study was to use data from a mature prospective randomized clinical trial that evaluated the use of RT versus RT and ADT as initial treatment in men with unfavorablerisk PC to ascertain whether a significant association existed between an increased risk of PC-specific mortality (PCSM) when salvage ADT was initiated at high versus lower PSA level among men with short versus long PSA-DTs after adjusting for age and known PC prognostic factors and previously identified interactions. ${ }^{12}$

\section{Methods}

\section{Patient Population, Treatment, and Follow-Up}

The study cohort was selected from 206 men with localized (1992 AJCC tumor category 1b to 2b) unfavorable (intermediate or high)-risk $\mathrm{PC}^{16}$ who underwent central pathology review and were enrolled in a randomized trial of RT or RT plus 6 months of ADT between December 1, 1995, and April 15, 2001. Information on eligibility criteria and patient characteristics stratified by randomized treatment arms was reported previously. ${ }^{5}$ D conformal RT was used to deliver $70.2 \mathrm{~Gy}$ in 39 fractions of 1.8 Gy per fraction to the prostate and seminal vesicles. Combined androgen blockade included 2 injections of a luteinizing hormone-releasing hormone (LHRH) agonist (leuprolide acetate, $22.5 \mathrm{mg}$ every 3 months or goserelin, $10.8 \mathrm{mg}$ every 3 months) and a nonsteroidal antiandrogen (flutamide, $250 \mathrm{mg}$ every 8 hours or bicalutamide, $50 \mathrm{mg}$ every day, discontinued on day 85 after the second administration of the LHRH agonist). Baseline comorbidity at the time of study enrollment was characterized using the Adult Comorbidity Evaluation-27 (ACE-27) index. ${ }^{17}$

Prior to PSA failure, patients were followed with PSA testing, physical examination, and digital rectal examination every 3 months for 2 years, then every 6 months until 5 years, and annually thereafter. ${ }^{5}$ If PSA failure occurred, bone scan and pelvic CT or MRI were performed. A total of 108 patients developed biochemical failure, defined as $2 \mathrm{ng} / \mathrm{mL}$ elevation higher than the lowest PSA value achieved. The study protocol recommended lifelong salvage ADT or bilateral orchiectomy when PSA levels approached $10 \mathrm{ng} / \mathrm{mL} .{ }^{18}$ Ultimately, 54 men (39 and 15 men randomized to RT vs RT + ADT, respectively) received salvage ADT $(n=50)$ or orchiectomy $(n=4)$ for PSA failure after a median follow-up of 18.72 years following randomization, and these men defined the study cohort as shown in the CONSORT diagram (Figure 1). The 54 remaining men with PSA failure were not treated with salvage ADT because their PSA levels remained $<10 \mathrm{ng} / \mathrm{mL}(\mathrm{n}=48)$ due to significant comorbid illness $(n=3)$ or because the ny had a PSA-DT $>2$ years and advanced age of $>75$ years $(n=3)$.

Time zero for this study commenced at the time of salvage ADT initiation and concluded on the date of death or last follow-up through September 6, 2016, with no patients lost to follow-up. The DanaFarber/Harvard Cancer Center Institutional Review Board granted permission to perform this study.

\section{Cause of Death Determination}

If a patient became refractory to first-line salvage ADT, second- and third-line ADT was used, usually followed by cytotoxic chemotherapy. Cause of death was determined by the treating oncologist who followed the patient from study entry until death. All cause-of-death determinations were reviewed and confirmed by the principal investigator of the study (A.V.D.).

\section{Statistical Methods}

Distribution and Comparison of Clinical Characteristics at Randomization: Descriptive statistics characterized the distribution of clinical characteristics for the 54 men in the study cohort, stratified by PSA-DT and PSA level at the time of salvage ADT. PSA-DT 


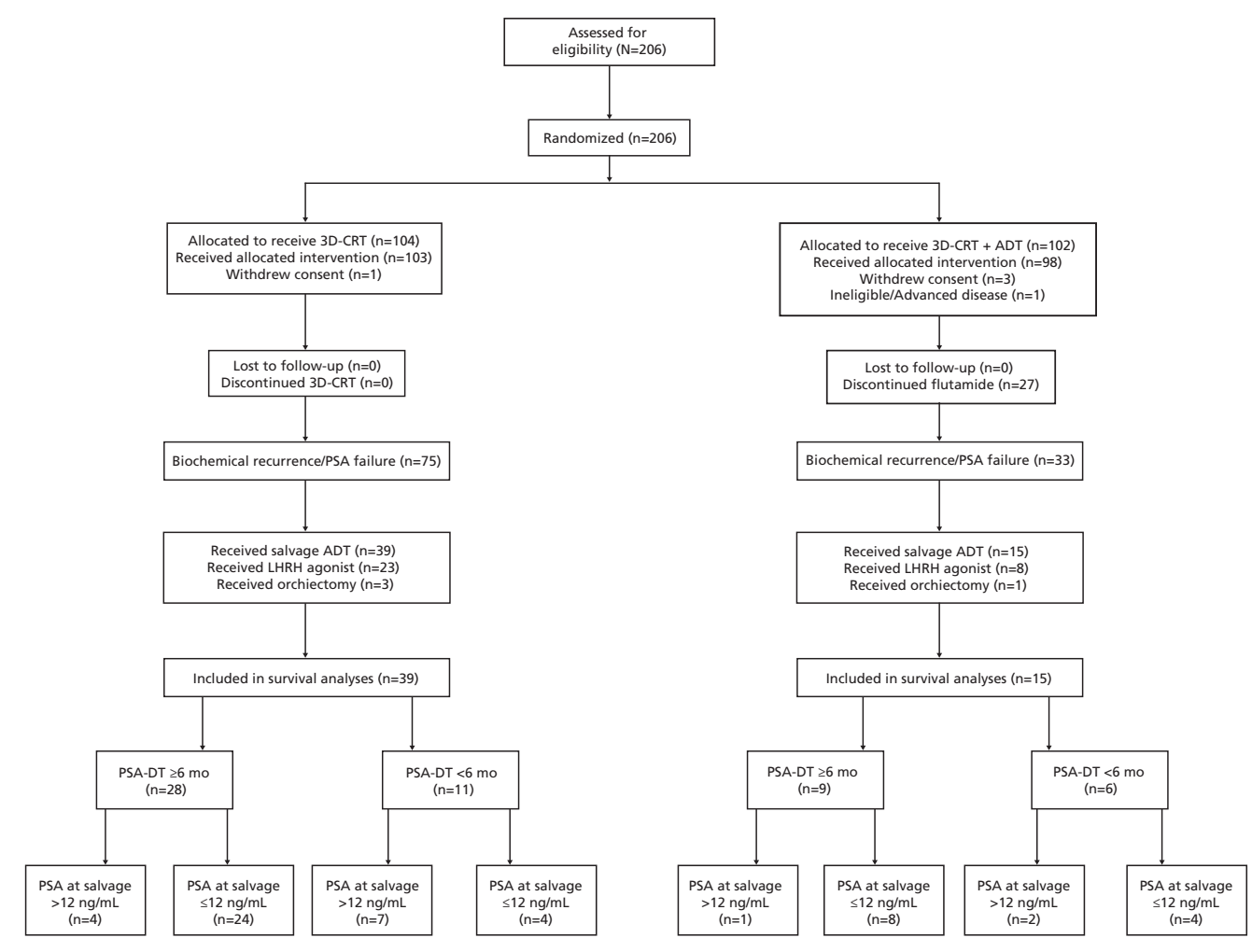

Figure 1. CONSORT diagram.

Abbreviations: 3D-CRT, 3D conformal radiation therapy; ADT, androgen deprivation therapy; LHRH, luteinizing hormone-releasing hormone; PSA, prostate-specific antigen; PSA-DT, prostate-specific antigen doubling time.

was stratified by $\geq 6$ versus $<6$ months because PSADT $<6$ months is a well-established poor prognostic factor associated with a high risk of subsequent distant metastases and death due to PC. ${ }^{18-21}$ PSA level at salvage $A D T$ was stratified by $>12 \mathrm{ng} / \mathrm{mL}$ versus $\leq 12 \mathrm{ng} /$ $\mathrm{mL}$ because $12.05 \mathrm{ng} / \mathrm{mL}$ represented the upper quartile and we sought to determine whether a delay in the initiation of salvage ADT using PSA level as a surrogate for timing of ADT was associated with a higher risk of PCSM among men with short ( $<6$ months) or long ( $\geq 6$ months) DTs. Wilcoxon rank sum ${ }^{22}$ and Fisher exact ${ }^{23}$ tests were used to compare the distribution of the continuous covariates and categorical covariates, respectively. The log rank test ${ }^{24}$ was used to compare the median survival times following salvage ADT in years. These comparisons were made across subgroups defined by the prespecified PSA-DT and PSA level cutpoints (ie, 6 months and 3rd quartile of $12 \mathrm{ng} / \mathrm{mL}$, respectively; Table 1).

Univariable and Multivariable Competing Risks Regressions: Univariable and multivariable FineGray competing risks regression analyses ${ }^{25}$ were per- formed to ascertain whether the timing of salvage ADT was significantly associated with an increased risk of PCSM adjusting for age, comorbidity, known $\mathrm{PC}$ prognostic factors, and previously identified interactions. Specifically, we included age, interval to PSA failure (continuous), PSA-DT (continuous), PSA level at time of salvage ADT (continuous), highest Gleason score ( $\leq 6$ [referent] vs 7 vs $8-10$ ), clinical tumor category (T1 [referent] vs T2), randomly assigned treatment arm (RT [referent] vs RT + ADT), and comorbidity status (no/minimal [referent] vs moderate/severe) in the primary model. The PSA-DT and PSA level were log transformed to ensure that the results followed a normal distribution. A "comorbidity x ADT" interaction term was also included because it was identified as a significant interaction in the randomized trial. ${ }^{5}$ In a second model, we categorized the PSA-DT split at 6 months and PSA level at time of salvage ADT split at $12 \mathrm{ng} /$ $\mathrm{mL}$ in order to generate a testable hypothesis regarding the risk of PCSM and early versus delayed initiation of salvage ADT among men with short versus long PSA-DTs. We also included an interaction term 
Mahal et al

\begin{tabular}{|c|c|c|c|c|c|c|}
\hline \multirow[b]{3}{*}{ Clinical Characteristics } & \multicolumn{3}{|c|}{ PSA-DT $\geq 6$ mo $(n=37)$} & \multicolumn{3}{|c|}{ PSA-DT $<6$ mo $(n=17)$} \\
\hline & \multicolumn{2}{|c|}{ PSA at Salvage } & \multirow[b]{2}{*}{$P$ Value } & \multicolumn{2}{|c|}{ PSA at Salvage } & \multirow[b]{2}{*}{$P$ Value } \\
\hline & $\begin{array}{c}>12 \mathrm{ng} / \mathrm{mL} \\
(\mathrm{N}=5)\end{array}$ & $\begin{array}{c}\leq 12 \mathrm{ng} / \mathrm{mL} \\
(\mathrm{N}=32)\end{array}$ & & $\begin{array}{c}>12 \mathrm{ng} / \mathrm{mL} \\
(\mathrm{N}=9)\end{array}$ & $\begin{array}{c}\leq 12 \mathrm{ng} / \mathrm{mL} \\
(\mathrm{N}=8)\end{array}$ & \\
\hline Median age at salvage (IQR), y & $\begin{array}{c}83.26 \\
(78.76-83.98)\end{array}$ & $\begin{array}{c}76.61 \\
(71.27-80.23)\end{array}$ & .09 & $\begin{array}{c}71.52 \\
(69.49-73.77)\end{array}$ & $\begin{array}{c}76.37 \\
(75.22-80.03)\end{array}$ & .09 \\
\hline Median interval to PSA failure (IQR), mo & $\begin{array}{c}43.89 \\
(19.25-71.13)\end{array}$ & $\begin{array}{c}37.75 \\
(24.92-53.42)\end{array}$ & .91 & $\begin{array}{c}14.32 \\
(8.71-21.52)\end{array}$ & $\begin{array}{c}23.16 \\
(19.37-58.78)\end{array}$ & .11 \\
\hline Median survival after salvage ADT (IQR), y & $\begin{array}{c}4.94 \\
(1.92-5.87)\end{array}$ & $\begin{array}{c}6.78 \\
(5.13-12.45)\end{array}$ & $.02^{\mathrm{a}}$ & $\begin{array}{c}3.23 \\
(2.07-5.20)\end{array}$ & $\begin{array}{c}3.10 \\
(2.87-7.29)\end{array}$ & $.29^{\mathrm{a}}$ \\
\hline \multicolumn{7}{|l|}{ AJCC clinical tumor category, $\mathrm{n}(\%)$} \\
\hline T1 & $2(40)$ & $14(43.75)$ & \multirow{2}{*}{1.00} & $2(22.22)$ & $2(25)$ & \multirow{2}{*}{1.00} \\
\hline $\mathrm{T} 2$ & $3(60)$ & $18(56.25)$ & & $7(77.78)$ & $6(75)$ & \\
\hline \multicolumn{7}{|l|}{ Highest Gleason score, n (\%) } \\
\hline$\leq 6$ & $2(40)$ & $9(28.13)$ & \multirow{3}{*}{.24} & $0(0)$ & $0(0)$ & \multirow{3}{*}{.62} \\
\hline 7 & $1(20)$ & $18(56.25)$ & & $5(55.56)$ & $6(75)$ & \\
\hline $8-10$ & $2(40)$ & $5(15.63)$ & & $4(44.44)$ & $2(25)$ & \\
\hline \multicolumn{7}{|l|}{ Randomly assigned intervention, $\mathrm{n}(\%)$} \\
\hline RT alone & $4(80)$ & $24(75)$ & \multirow{2}{*}{1.00} & 7 (77.78) & $4(50)$ & \multirow{2}{*}{.33} \\
\hline $\mathrm{RT}+\mathrm{ADT}$ & $1(20)$ & $8(25)$ & & $2(22.22)$ & $4(50)$ & \\
\hline \multicolumn{7}{|l|}{ ACE-27-defined comorbidity } \\
\hline No/Minimal & $3(60)$ & $24(75)$ & \multirow{2}{*}{.60} & $9(100)$ & $7(87.5)$ & \multirow{2}{*}{.47} \\
\hline Moderate/Severe & $2(40)$ & $8(25)$ & & $0(0)$ & $1(12.5)$ & \\
\hline
\end{tabular}

Abbreviations: ACE-27, Adult Comorbidity Evaluation-27; ADT, androgen deprivation therapy; IQR, interquartile range; PSA, prostate-specific antigen; PSA-DT, prostate-specific antigen doubling time; RT, radiation therapy. aLog-rank test $P$ values.

between PSA-DT and PSA level at time of salvage ADT to ascertain whether an increase in PCSM risk could exist in men with long but not short PSA-DTs when salvage ADT was initiated at a higher versus lower PSA level. Unadjusted and adjusted hazard ratios (HRs) and associated 95\% CIs with associated $P$ values were calculated for each covariate.

Estimates of PCSM: For the purposes of illustration, cumulative incidence plots $^{26}$ for PCSM were generated stratified by PSA-DT ( $\geq 6$ vs $<6$ months) and PSA level ( $>12 \mathrm{vs} \leq 12 \mathrm{ng} / \mathrm{mL}$ ) at the time of salvage ADT. These estimates were compared across subgroups using Gray's K-mean $P$ value. ${ }^{25}$ The median follow-up for the study was 5.68 years and as such, 5-year point estimates of PCSM with associated 95\% CIs were calculated and reported stratified by subgroup.

All $P$ values were 2 -sided, with $P<.025$ considered significant after Bonferroni corrections $(n=2$ PSA-DT groups) were made for multiple comparisons. ${ }^{27}$ All analyses were performed using SAS 9.4 (SAS Institute), except for the PCSM estimates and
Gray's K-mean $P$ value, which was calculated using $R$ version 3.2.3 (R Foundation).

\section{Results}

\section{Distribution and Comparison of Clinical Characteristics at Randomization}

There was no significant difference in the distribution of patients, cancer, and treatment characteristics among men with a PSA-DT of $<6$ versus $\geq 6$ months who started salvage ADT at a PSA level that exceeded the $3 \mathrm{rd}$ quartile (PSA level $>12 \mathrm{ng} /$ $\mathrm{mL}$ ) versus those who did not (Table 1$)$. However, a significantly shorter median survival (4.94 vs 6.78 years; $P=.02$ ) was seen in men with a long PSA-DT ( $\geq 6$ months) and a PSA level $>12 \mathrm{ng} / \mathrm{mL}$ at the time of salvage ADT compared with $\leq 12 \mathrm{ng} / \mathrm{mL}$.

\section{Univariable and Multivariable Competing Risks Regressions}

After a median follow-up of 5.68 years (interquartile range, 3.05-9.56), 49 of 54 men died (91\%), with 27 deaths due to PC (accounting for 54\% of 
Salvage ADT After Biochemical Recurrence

deaths). PSA-DT, when evaluated as a continuous covariate (per month increase), was significantly associated with a decreasing risk of PCSM as the value of PSA-DT increased (Table 2, footnote). Moreover, among men with a long PSA-DT ( $\geq 6$ months), initiating salvage ADT later (at PSA level $>12 \mathrm{ng}$ / $\mathrm{mL}$ ) as opposed to earlier was associated with an increased risk of PCSM (adjusted HR, 8.84; 95\% CI, $1.99-39.27 ; P=.004)$. However, this was not seen for men with a short PSA-DT ( $<6$ months; adjusted HR, 1.16; 95\% CI, 0.38-3.54; P=.79). As a result, the interaction term between PSA-DT and PSA level at salvage was significant in the multivariable analysis $\left(P_{\text {interaction }}=.05\right)$.

\section{Estimates of PCSM}

As shown in Figure 2A, cumulative incidence estimates of PCSM were significantly higher ( $\mathrm{K}$-mean
$P$ value=.014) among men with a PSA-DT $\geq 6$ months who started salvage ADT at PSA level $>12$ $\mathrm{ng} / \mathrm{mL}$ as opposed to PSA level $\leq 12 \mathrm{ng} / \mathrm{mL}$. However, these estimates were not significantly different (K-mean $P$ value=.16) among men with a PSADT $<6$ months, as shown in Figure 2B. Specifically, among men with a PSA-DT $\geq 6$ months, the 5 -year cumulative incidence point estimates of PCSM were 40.0\% (95\% CI, 2.58-79.48) versus 6.25\% (95\% CI, 1.07-18.37) among men who started salvage ADT at PSA level $>12 \mathrm{ng} / \mathrm{mL}$ as opposed to PSA level $\leq 12$ $\mathrm{ng} / \mathrm{mL}$. In comparison, among men with a PSA-DT $<6$ months, the 5-year cumulative incidence point estimates of PCSM were 55.56\% (95\% CI, 17.4782.03 ) versus $50.0 \%$ (95\% CI, 12.05-79.69) when salvage ADT was imitated at PSA level $>12 \mathrm{ng} / \mathrm{mL}$ as opposed to PSA level $\leq 12 \mathrm{ng} / \mathrm{mL}$.

\begin{tabular}{|c|c|c|c|c|c|c|}
\hline \multirow[b]{2}{*}{ Clinical Characteristics } & \multirow[b]{2}{*}{ Men, $\mathrm{n}$} & \multirow[b]{2}{*}{ Deaths, $\mathrm{n}$} & \multicolumn{2}{|c|}{ Univariable Analysis } & \multicolumn{2}{|c|}{ Multivariable Analysis } \\
\hline & & & HR $(95 \%$ Cl) & $P$ Value & AHR $(95 \% \mathrm{Cl})$ & $P$ Value \\
\hline PSA-DT x PSA level at salvage ADT & 54 & 27 & $0.63(0.10-3.84)$ & .62 & $0.13(0.02-1.03)$ & .05 \\
\hline \multicolumn{7}{|l|}{ PSA-DT $\geq 6 \mathrm{mo}^{\mathrm{a}}$} \\
\hline $\mathrm{PSA} \leq 12 \mathrm{ng} / \mathrm{mL}$ & 32 & 10 & 1.00 (Ref) & & 1.00 (Ref) & \\
\hline PSA $>12 \mathrm{ng} / \mathrm{mL}$ & 5 & 3 & $4.26(1.53-11.86)$ & .006 & $8.84(1.99-39.27)$ & .004 \\
\hline \multicolumn{7}{|l|}{ PSA-DT $<6 \mathrm{mo}^{\mathrm{a}}$} \\
\hline $\mathrm{PSA} \leq 12 \mathrm{ng} / \mathrm{mL}$ & 8 & 6 & 1.00 (Ref) & & 1.00 (Ref) & \\
\hline PSA $>12 \mathrm{ng} / \mathrm{mL}$ & 9 & 8 & $1.85(0.57-6.01)$ & .30 & $1.16(0.38-3.54)$ & .79 \\
\hline Age, y & 54 & 27 & $0.95(0.89-1.004)$ & .07 & $0.98(0.90-1.07)$ & .65 \\
\hline Interval to PSA failure, mo & 54 & 27 & $0.96(0.94-0.99)$ & .003 & $0.97(0.94-1.003)$ & .08 \\
\hline \multicolumn{7}{|l|}{ AJCC clinical tumor category } \\
\hline T1 & 20 & 8 & 1.00 (Ref) & & 1.00 (Ref) & \\
\hline $\mathrm{T} 2$ & 34 & 19 & $1.71(0.77-3.80)$ & .19 & $1.33(0.52-3.37)$ & .55 \\
\hline \multicolumn{7}{|l|}{ Highest Gleason score } \\
\hline$\leq 6$ & 11 & 2 & 1.00 (Ref) & & 1.00 (Ref) & \\
\hline 7 & 30 & 17 & $4.03(1.02-15.89)$ & .046 & $3.19(0.84-12.12)$ & .09 \\
\hline $8-10$ & 13 & 8 & $5.43(1.19-24.64)$ & .03 & $4.39(0.83-23.34)$ & .08 \\
\hline ADT $x$ comorbidity & 54 & 27 & $2.21(0.15-32.26)$ & .56 & $3.88(0.24-63.20)$ & .34 \\
\hline \multicolumn{7}{|c|}{ No/Minimal ACE-27-defined comorbidity } \\
\hline RT & 31 & 19 & 1.00 (Ref) & & 1.00 (Ref) & \\
\hline $\mathrm{RT}+\mathrm{ADT}$ & 12 & 4 & $0.48(0.16-1.44)$ & .19 & $0.35(0.06-1.97)$ & .24 \\
\hline \multicolumn{7}{|c|}{ Moderate/Severe ACE-27-defined comorbidity } \\
\hline RT & 8 & 3 & 1.00 (Ref) & & 1.00 (Ref) & \\
\hline $\mathrm{RT}+\mathrm{ADT}$ & 3 & 1 & $1.05(0.09-12.14)$ & .97 & $1.37(0.19-9.88)$ & .75 \\
\hline
\end{tabular}

Abbreviations: ACE-27, Adult Comorbidity Evaluation-27; ADT, androgen deprivation therapy; AHR, adjusted hazard ratio; HR, hazard ratio; IQR, interquartile range; PSA, prostate-specific antigen; PSA-DT, prostate-specific antigen doubling time; RT, radiation therapy.

aWhen PSA-DT and level (both after log transformation) at time of salvage ADT were treated as continuous covariates and without an interaction term, the AHRs are $0.33(95 \% \mathrm{Cl}, 0.13-0.82 ; P=.02)$ and $1.27(95 \% \mathrm{Cl}, 0.69-2.32 ; P=.44)$, respectively. 
Mahal et al
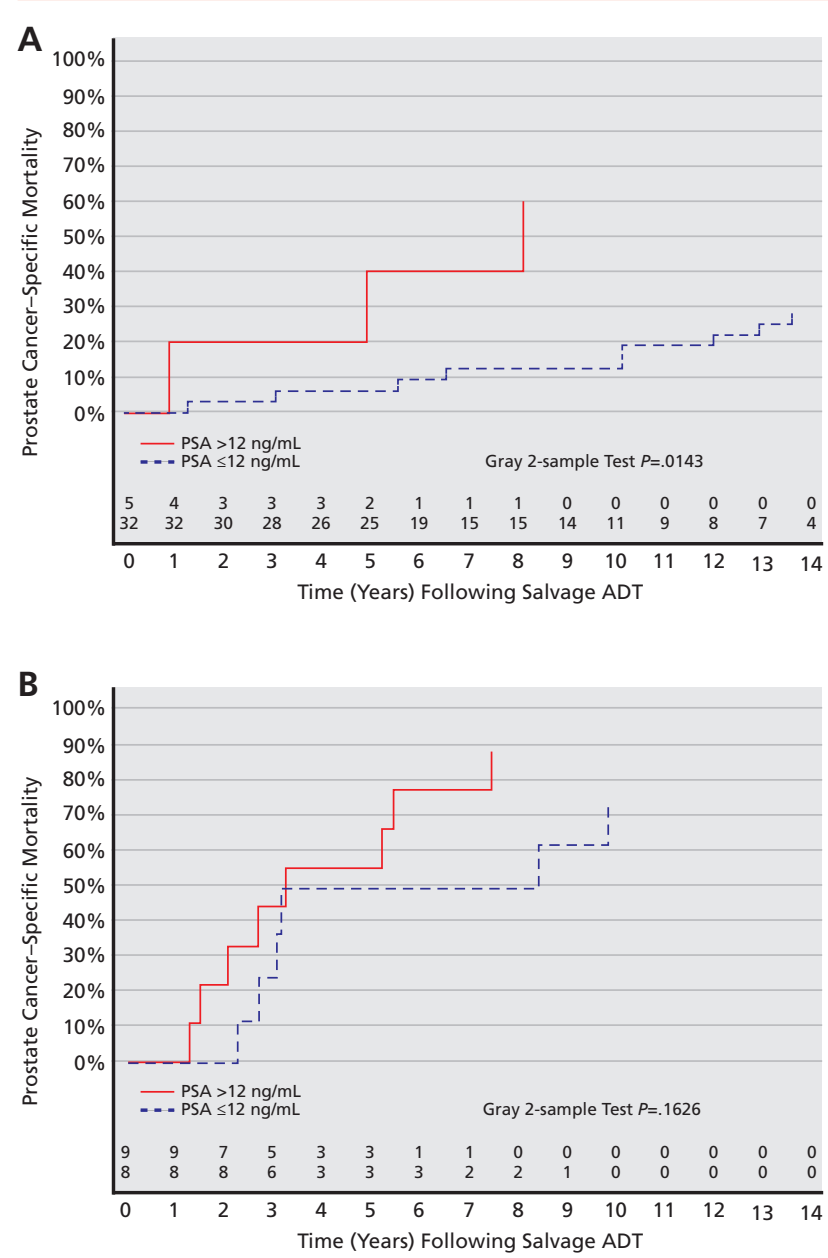

Figure 2. PCSM plots for PSA-DT of $(A) \geq 6$ months and $(B)<6$ months, stratified by PSA at time of initiation of salvage ADT (PSA $>12 \mathrm{ng} / \mathrm{mL}$ vs PSA $\leq 12 \mathrm{ng} / \mathrm{mL}$ ).

Abbreviations: ADT, androgen deprivation therapy; PCSM, prostate cancer-specific mortality; PSA, prostate-specific antigen; PSA-DT, prostate-specific antigen doubling time.

\section{Discussion}

Among men with long PSA-DTs ( $\geq 6$ months), the risk of dying from $\mathrm{PC}$ was found to be significantly greater with initiation of salvage ADT at a PSA level that exceeded the 3rd quartile (PSA level $>12$ $\mathrm{ng} / \mathrm{mL}$ ) compared with salvage ADT initiation at a lower PSA level $(\leq 12 \mathrm{ng} / \mathrm{mL})$. In contrast, we found that PSA level at the time of salvage ADT initiation did not significantly impact the risk of PCSM among men with short PSA-DTs ( $<6$ months).

The clinical significance of these observations is that they provide evidence to argue against the unproven assumption that patients with a short PSA-DT are those most likely to benefit from early initiation of salvage ADT. As such, our results raise a question

regarding the current NCCN Guideline recommendations encouraging earlier salvage ADT initiation specifically in men with short PSA-DTs. ${ }^{2,15,28-30}$ Instead, consideration of earlier initiation of salvage ADT in men with a long PSA-DT may be appropriate for some. Moreover, for a subgroup of these men with additional favorable prognostic factors (long interval to PSA failure and favorable risk disease), a reduction in the risk of PCSM from salvage local therapy alone may be possible. ${ }^{31}$ Conversely, men with short PSA-DTs may be optimal candidates for enrollment in randomized controlled trials evaluating the impact on time to metastasis and survival from adding drugs such as enzalutamide, docetaxel, and/or abiraterone, which have been shown to improve survival in men with recurrent, metastatic, and castration-resistant PC previously treated with a standard LHRH agonist. ${ }^{32-35}$

Several points require further discussion. First, our results show an association and not causality between a lower risk of PCSM and initiation of salvage ADT at lower PSA levels in men with long PSADTs. To date, only a single randomized trial shows a survival benefit with early versus delayed salvage ADT (HR, 0.55; 95\% CI, 0.30-1.00; P=.05) in a group of diverse patients who experienced PSA relapse after surgery or RT as initial definitive therapy, or who were medically unfit for definitive therapy. ${ }^{15}$ Although that study was stratified by a PSA-DT of 10 months, ${ }^{15}$ there was no report of these results stratified by PSA-DT in the post-RT cohort. Remaining evidence is level 2, including data from an observational follow-up study and a systematic review suggesting that the benefit of early salvage ADT is limited to men with short PSA-DTs, ${ }^{12,13}$ whereas data from the CaPSURE study suggested similar outcomes between early and delayed salvage ADT approaches. ${ }^{14}$ Therefore, proof that the association we observed in the significantly shorter median survival in men with a PSA-DT of $\geq 6$ months who started salvage ADT later versus earlier is causal requires prospective validation in a larger study than ours, wherein only 17 and 37 men were in the short versus long PSA-DT subgroups, respectively.

Second, although men with short PSA-DTs did not appear to have an increased risk of PCSM despite whether salvage ADT was started at high versus low PSA levels, this may be a result of the fact that all PSA levels at which salvage ADT was initiated 
were high. This stems from a fact that a PSA level of $10 \mathrm{ng} / \mathrm{mL}$ was used in our prospective study to define when salvage ADT should be initiated, which was common practice in the late 1990s into early 2000s when we conducted this study. It is possible that salvage ADT initiation at lower PSA levels, as commonly practiced today, could lead to a reduced risk of PCSM even in men with short PSA-DTs. However, given that short PSA-DTs have been shown to place men at a higher risk for, and in some studies have been used as a surrogate end point for, PCSM and all-cause mortality, ${ }^{19,20,36}$ it is likely that such men may already have metastatic castration-resistant PC for whom conventional salvage ADT with an LHRH agonist may not be effective. This supports our pro- posal to enroll such men onto randomized trials in which drugs capable of overcoming castration resistance, ${ }^{34,35,37}$ such as abiraterone, enzalutamide, and docetaxel, are added to the LHRH agonist and the impact on time to metastasis and death is evaluated.

\section{Conclusions}

The results of this small cohort of patients sets the stage for further investigation in larger studies to determine whether early initiation of salvage ADT at lower absolute PSA levels for biochemical recurrence in the setting of long PSA-DT ( $\geq 6$ months) reduces the risk of PCSM.

\section{References}

1. Siegel RL, Miller KD, Jemal A. Cancer statistics, 2017. CA Cancer J Clin 2017;67:7-30.

2. Mohler JL, Lee RJ, Antonarakis ES, et al. NCCN Clinical Practice Guidelines in Oncology: Prostate Cancer. Version 2.2018. Accessed March 30, 2017. To view the most recent version of these guidelines, visit NCCN. org.

3. Jones CU, Hunt D, McGowan DG, et al. Radiotherapy and shortterm androgen deprivation for localized prostate cancer. N Engl J Med 2011;365:107-118.

4. Wilt TJ, Brawer MK, Jones KM, et al. Radical prostatectomy versus observation for localized prostate cancer. N Engl J Med 2012;367:203-213.

5. D'Amico AV, Chen MH, Renshaw AA, et al. Androgen suppression and radiation vs radiation alone for prostate cancer: a randomized trial. JAMA 2008;299:289-295.

6. D'Amico AV, Renshaw AA, Sussman B, Chen MH. Pretreatment PSA velocity and risk of death from prostate cancer following external beam radiation therapy. JAMA 2005;294:440-447.

7. Freedland SJ, Humphreys EB, Mangold LA, et al. Risk of prostate cancer-specific mortality following biochemical recurrence after radical prostatectomy. JAMA 2005;294:433-439.

8. Roach M III, Hanks G, Thames H Jr, et al. Defining biochemical failure following radiotherapy with or without hormonal therapy in men with clinically localized prostate cancer: recommendations of the RTOGASTRO Phoenix Consensus Conference. Int J Radiat Oncol Biol Phys 2006;65:965-974.

9. Moul JW. Prostate specific antigen only progression of prostate cancer. J Urol 2000;163:1632-1642.

10. Shipley WU, Seiferheld W, Lukka HR, et al. Radiation with or without antiandrogen therapy in recurrent prostate cancer. $\mathrm{N}$ Engl J Med 2017;376:417-428.

11. Carrie C, Hasbini A, de Laroche G, et al. Salvage radiotherapy with or without short-term hormone therapy for rising prostate-specific antigen concentration after radical prostatectomy (GETUG-AFU 16): a randomised, multicentre, open-label phase 3 trial. Lancet Oncol 2016;17:747-756.

12. Fu AZ, Tsai HT, Haque R, et al. Mortality and androgen deprivation therapy as salvage treatment for biochemical recurrence after primary therapy for clinically localized prostate cancer. J Urol 2017;197:1448-1454.

13. van den Bergh RC, van Casteren NJ, van den Broeck T, et al. Role of hormonal treatment in prostate cancer patients with nonmetastatic disease recurrence after local curative treatment: a systematic review. Eur Urol 2016;69:802-820.

14. Garcia-Albeniz X, Chan JM, Paciorek A, et al. Immediate versus deferred initiation of androgen deprivation therapy in prostate cancer patients with PSA-only relapse. An observational follow-up study. Eur J Cancer 2015;51:817-824.

15. Duchesne GM, Woo HH, Bassett JK, et al. Timing of androgen-deprivation therapy in patients with prostate cancer with a rising PSA (TROG 03.06 and VCOG PR 01-03 [TOAD]): a randomised, multicentre, non-blinded, phase 3 trial. Lancet Oncol 2016;17:727-737.

16. D'Amico AV, Whittington R, Malkowicz SB, et al. Biochemical outcome after radical prostatectomy, external beam radiation therapy, or interstitial radiation therapy for clinically localized prostate cancer. JAMA 1998;280:969-974.

17. Piccirillo JF, Tierney RM, Costas I, et al. Prognostic importance of comorbidity in a hospital-based cancer registry. JAMA 2004;291:24412447.

18. Prostate-specific antigen (PSA) best practice policy. American Urological Association (AUA). Oncology (Williston Park) 2000;14:267-272, 277278, 280 passim

19. D'Amico AV, Moul J, Carroll PR, et al. Prostate specific antigen doubling time as a surrogate end point for prostate cancer specific mortality following radical prostatectomy or radiation therapy. J Urol 2004;172:S4246; discussion S46-47.

20. Pound CR, Partin AW, Eisenberger MA, et al. Natural history of progression after PSA elevation following radical prostatectomy. JAMA 1999;281:1591-1597.

21. Patel A, Dorey F, Franklin J, deKernion JB. Recurrence patterns after radical retropubic prostatectomy: clinical usefulness of prostate specific antigen doubling times and log slope prostate specific antigen. J Urol 1997;158:1441-1445.

22. Hollander M, Wolfe DA. Nonparametric Statistical Methods, 2nd ed. New York, NY: John Wiley \& Sons; 1999.

23. Fisher RA. On the interpretation of $X 2$ from contingency tables, and the calculation of P. J R Stat Soc 1922;85:87-94.

24. Bland JM, Altman DG. The logrank test. BMJ 2004;328:1073.

25. Fine J, Gray R. A proportional hazards model for the subdistribution of a competing risk. J Am Stat Assoc 1999;94:496-509.

26. Gaynor JJ, Feuer EJ, Tan CC, et al. On the use of cause-specific failure and conditional failure probabilities: examples from clinical oncology data. J Am Stat Assoc 1993;88:400.

27. Bland JM, Altman DG. Multiple significance tests: the Bonferroni method. BMJ 1995;310:170.

28. Garcia-Albeniz X, Chan JM, Paciorek AT, et al. Immediate versus deferred initiation of androgen deprivation therapy in prostate cancer patients with PSA-only relapse [abstract]. J Clin Oncol 2014;32(Suppl):Abstract 5003.

29. Mahal BA, Chen MH, Bennett CL, et al. High PSA anxiety and low health literacy skills: drivers of early use of salvage ADT among men with biochemically recurrent prostate cancer after radiotherapy? Ann Oncol 2015;26:1390-1395.

30. Moreira DM, Banez LL, Presti JC Jr, et al. Predictors of secondary treatment following biochemical recurrence after radical prostatectomy: results from the Shared Equal Access Regional Cancer Hospital database. BJU Int 2010;105:28-33. 
31. Lee AK, D'Amico AV. Utility of prostate-specific antigen kinetics in addition to clinical factors in the selection of patients for salvage local therapy. J Clin Oncol 2005;23:8192-8197.

32. Sweeney CJ, Chen YH, Carducci M, et al. Chemohormonal therapy in metastatic hormone-sensitive prostate cancer. N Engl J Med 2015;373:737746.

33. James ND, de Bono JS, Spears MR, et al. Abiraterone for prostate cancer not previously treated with hormone therapy. N Engl J Med 2017;377:338-351.

34. de Bono JS, Logothetis CJ, Molina A, et al. Abiraterone and increased survival in metastatic prostate cancer. N Engl J Med 2011;364:1995-2005.
35. Scher HI, Fizazi K, Saad F, et al. Increased survival with enzalutamide in prostate cancer after chemotherapy. N Engl J Med 2012;367:1187-1197.

36. Royce TJ, Chen MH, Wu J, et al. Surrogate end points for all-cause mortality in men with localized unfavorable-risk prostate cancer treated with radiation therapy vs radiation therapy plus androgen deprivation therapy: a secondary analysis of a randomized clinical trial. JAMA Oncol 2017;3:652-658

37. Petrylak DP, Tangen CM, Hussain MH, et al. Docetaxel and estramustine compared with mitoxantrone and prednisone for advanced refractory prostate cancer. N Engl J Med 2004;351:1513-1520.

\section{Register now at NCCN.org/academy}

\section{NCCN Academy for Excellence \& Leadership in Oncology ${ }^{\mathrm{TM}}$ School of Pharmaceutical \& Biotech Business}

Tuesday, July 10, 2018 • 8:50 AM - 2:15 PM The Rittenhouse $\bullet$ Philadelphia, Pennsylvania

(Breakfast and registration begin at 8:00 AM)

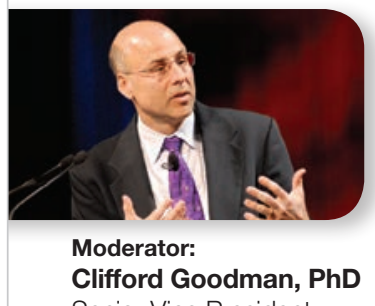

Senior Vice President

The Lewin Group
Module I: Who Exactly is the Payer? A View Across the Oncology Ecosystem

Module II: Meet the NCCN Guidelines ${ }^{\circledR}$ Panel Experts

Module III: Incorporating the Patient Voice in Shared Decision Making

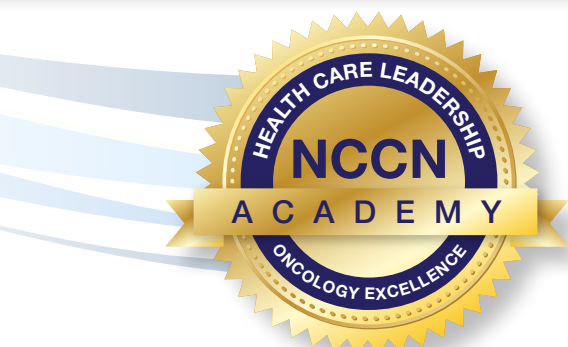

Celebrating 10 years!

By attending, professionals will be able to:

- Hear directly from NCCN Guidelines ${ }^{\circledast}$ Panel Members;

- Improve working knowledge of key business, policy, coverage, reimbursement, informational, and operational issues in oncology;

- Gather valuable insights into developing effective strategies for navigating the various constituencies in cancer care.

Visit NCCN.org/academy to enroll and to access the complete program curriculum. 